\title{
Fatores Motivadores do Empreendedorismo e as Decisões Estratégicas de Pequenas Empresas
}

\author{
Motivational Factors Entrepreneurship and Strategic Decisions \\ Small Business
}

Siomara Elias Vicenzi

Mestra em Administração pela Universidade Federal do Paraná - Curitiba - PR, Brasil. E-mail: siomaravicenzi@gmail.com

Sergio Bulgacov

Doutor em Administração de Empresas pela FGV- SP e docente da EAESP - FGV - São Paulo - SP, Brasil. E-mail: s.bulgacov@gmail. com

\section{Resumo}

O propósito deste trabalho é compreender os fatores motivadores que influenciaram ações empreendedoras estratégicas de pequenos empresários da região sul do Brasil. A pesquisa é descritiva, de natureza quantitativa, do tipo levantamento e realizada por meio de investigação de campo em 100 atividades empreendedoras, de pequeno porte, da região sul do Brasil. Os resultados demonstram as características pessoais dos empreendedores que mais se destacaram; os fatores motivadores na escolha de produtos, serviços e mercados; os fatores motivadores na decisão de abrir um negócio; os fatores motivadores na decisão de mudar o negócio, bem como as prováveis relações entre fatores motivadores e as mudanças de produtos e mercados. Os fatores que mais contribuíram desde a decisão inicial de seus negócios até as modificações de produtos e mercados foram: conhecimento teórico; conhecimento do setor; experiências dos empreendedores; avanços da tecnologia; e a dinâmica do mercado em termos econômicos e sociais.

Palavras-chave: Empreendedorismo. Características dos Empreendedores. Fatores Motivadores do Empreendedorismo. Conteúdo Estratégico, Pequena Empresa.

\section{Abstract}

The purpose of this study is to understand the motivating factors that have influenced strategic entrepreneurial activities of small entrepreneurs from the southern of Brazil. The research is descriptive, quantitative, survey-type and carried through field investigation in 100 entrepreneurial activities, small size. The results demonstrate the personal characteristics of entrepreneurs that stood out; the motivating factors in the choice of products, services and markets; the motivating factors in the decision to open a business; the motivating factors in the decision to change the business, and the probable relationship between motivating factors and changes in products and markets. The factors that contributed to the decision, since the initial choice of their business to the changes in products and markets were: theoretical knowledge; Industry knowledge; experiences of entrepreneurs; advances in technology; and market dynamics in economic and social terms.

Key words: Entrepreneurship. Characteristics of Entrepreneurs. Motivating Factors of Entrepreneurship. Strategic Content. Small Firms. 


\section{INTRODUÇÃo}

Há muitos estudos sobre empreendedorismo, mas poucos sobre empreendedorismo e estratégia. Por essa razão, este artigo tem como objetivo analisar e compreender os fatores motivadores do empreendedorismo que influenciam nas decisões de conteúdo estratégico nas empresas da região sul do país.

O papel do empreendedor está cada vez mais valorizado e neste processo é relevante observar as características dos empreendedores. Para Angelo (2003), a vontade e a habilidade para criar algo absolutamente novo, a capacidade para encontrar novas utilidades para velhas ideias e o talento para melhorar a eficiência de um sistema, processo ou produto são características fundamentais. A motivação é outra característica, pois, para Knudson et al. (2004), os empreendedores são indivíduos altamente motivados para iniciar novos empreendimentos, lançar novos produtos ou abrir novos mercados.

Quanto à motivação para abrir um negócio, os empreendedores podem ser orientados pela oportunidade ou pela necessidade, de acordo com o GEM (2009). Os fatores motivadores que levam as pessoas a abrirem seus negócios são os mais diversos, dentre eles destacam-se: necessidade de realização pessoal, percepção de oportunidade no mercado, problemas com o trabalho anterior, entre outros. (MACHADO et al., 2003)

Quanto aos fatores antecedentes que influenciam nas decisões de produtos, serviços e mercados foram identificados: o conhecimento prévio e a atividade exercida anteriormente pelos empreendedores, formação acadêmica, a família como modelo empreendedor, entre outros (MACHADO et al., 2003). De acordo com pesquisa realizada em onze estados brasileiros pelo SEBRAE (acesso em 2010), quanto maior o conhecimento $e$ as experiências vividas no negócio que se pretende atuar, maiores são as chances de sucesso.

Outro fator fundamental no processo de empreender é a escolha da estratégia. Para Bhide (2002), uma estratégia sólida é mais relevante para uma empresa iniciante, do que a contratação de pessoal. De acordo com Mintzberg e Quinn (2001), uma estratégia pode ser desenvolvida e formulada e na sequência implementada, seguindo um processo formal, ou ainda, pode surgir em resposta a uma situação que a exige, daí a sensibilidade do empreendedor às contingências de mercado.

Este artigo foi estruturado da seguinte maneira: empreendedorismo e o empreendedor; fatores motivadores do empreendedorismo; empreendedorismo $e$ estratégia, metodologia utilizada; análise dos dados e considerações finais.

\section{Empreendedorismo e o EMPREENDEDOR}

No Brasil, a estabilidade econômica e a manutenção do regime democrático, segundo o relatório GEM (2009), têm criado oportunidades para novas conquistas da atividade empreendedora.

A palavra empreendedorismo, de origem francesa (entrepreneur), significa aquele que assume riscos e começa algo novo (DORNELAS, 2001). É usada para distinguir o "patrão" que também é o dono, do administrador profissional e dos empregados. Fillion (1999) faz uma distinção entre o papel empreendedor e o proprietário de pequenos negócios. Destaca que muitas pessoas têm um papel empreendedor, sem terem criado uma empresa. Outros são proprietários de pequenos negócios porque compraram em vez de criá-los e não apresentam papel empreendedor. Para Gartner (1988), o empreendedorismo também está relacionado com a criação de empresas.

Outra relação do empreendedorismo é com a inovação e a vantagem competitiva, pois o empreendedor inova e a inovação é o instrumento específico do espírito empreendedor (CAROLIS; SAPARITO, 2006; DRUCKER, 2003). De acordo com o relatório GEM (2009), a atividade empreendedora que traz inovação e nova riqueza à economia está amplamente evidenciada.

No processo de empreender, as características pessoais ganham destaque, porém para Gartner (1988), os traços pessoais referem-se a uma parcela apenas no processo de empreender, pois a criação de empresas é bastante complexa e influenciada por vários fatores. $\mathrm{O}$ autor destaca que as pesquisas sobre o empreendedorismo deveriam focar sobre o que o empresário faz e não no que o empresário é.

As principais características pessoais citadas pelos diversos autores foram: assumir riscos, criatividade, inovação, iniciativa, autonomia, experiência, desejo 
de independência, know-how, coragem, motivação, entre outras. (DORNELAS, 2001; CRESPAN et al., 2009; GELDEREN, 2000; COSTIGAN et al., 2006; ANGELO, 2003; DRUCKER, 2003; KNUDSON et al., 2004; SCHUMPETER, 1982; BHIDE, 2001)

Além das características pessoais, há outras características a serem ressaltadas como, por exemplo, a faixa etária e o gênero, feminino e masculino, que predominam nos empreendimentos no país. A faixa etária que prevalece é a dos 25 aos 34 anos, com $31,7 \%$ e a diferença entre a participação de mulheres e de homens na atividade empreendedora é pequena: as mulheres aparecem com $53 \%$ e os homens com $47 \%$. O grau de instrução é outro fator a ser considerado. $\mathrm{Na}$ pesquisa realizada por Crespam et al. (2009), todos os entrevistados, com exceção de um, eram graduados e buscavam algum curso de pós-graduação. Na pesquisa de Machado et al. (2003) 63,28\% das entrevistadas também eram graduadas ou pós-graduadas.

Criar seu próprio negócio nem sempre é uma tarefa fácil. Pelas estatísticas do SEBRAE (acesso em 2010), o índice de mortalidade das micro e pequenas empresas brasileiras, nos primeiros cinco anos de existência, oscilam em torno dos $70 \%$ ou mais. Esses microempresários, segundo Bhide (2001), geralmente não possuem o conceito de negócios, atuando de forma empírica e sem planejamento estratégico. O autor também considera importantes a experiência, o know-how em negociação, a administração de despesas operacionais, as habilidades gerenciais, operacionais e de liderança, bem como a capacidade de atrair, reter e equilibrar os interesses dos investidores, clientes, empregados e fornecedores.

Segundo Dornelas (2001), muitos empreendedores só conseguem ser bem-sucedidos no segundo ou terceiro negócio. Aponta para a importância do empreendedor entender suas limitações e aprender com seus erros para não voltar a cometê-los em um novo empreendimento. Esses microempresários, segundo Bhide (2001), geralmente não possuem o conceito de negócios, atuando de forma empírica e sem planejamento.

A capacidade do empreendedor de prever o futuro com algum grau de detalhamento é limitada de acordo com Ansoff (1991). Mats e Wincent (2008) também destacam que, embora alguns executivos possam ter sido bem-sucedidos no passado, não há garantias de que sejam no futuro. Daí a importância do empreendedor adequar o uso das estratégias aos seus negócios visando a alcançar um diferencial competitivo.

\section{Fatores Motivadores do EMPREENDEDORISMO}

A seguir, são apresentados os fatores motivadores citados pela literatura que antecedem a abertura do negócio e os fatores motivadores na escolha de produtos, serviços e mercados.

\subsection{Fatores Motivadores que Antecedem a Abertura do Negócio}

A motivação do comportamento do empreendedor para a abertura de novos negócios, de acordo com o relatório GEM (2009), apresenta duas forças propulsoras: a oportunidade e a necessidade. Oportunidade decorre quando se investe em um novo negócio a fim de aproveitar uma circunstância favorável percebida no mercado. Necessidade é consequência da criação de um negócio pela falta de alternativa satisfatória de trabalho e renda, quando essa é a melhor opção disponível num determinado período.

Valliere (2010) corrobora com a pesquisa do GEM (2009), quanto à motivação do empreendedorismo por oportunidade ou por necessidade. Para o autor, quando a motivação é por oportunidade e não por necessidade, os empresários podem escolher a melhor opção, ou seja, os negócios podem se cruzar com a capacidade empresarial. O empreendedor, além de perceber a oportunidade, também precisa estar consciente de que possui a capacidade necessária para iniciar o negócio. (GEM, 2009)

Segundo Miao e Liu (2010), em pesquisa realizada com 327 empresários, num total de 158 empresas, os resultados indicaram que os fatores psicológicos do indivíduo (estar atento ao mercado e conhecimento prévio) têm papel fundamental no reconhecimento da oportunidade empresarial e influenciam na tomada de decisão. O conhecimento prévio, segundo os autores, antecede o reconhecimento de oportunidades e impacta diretamente na tomada de decisões.

Para outros pesquisadores, porém, é possível ter uma intenção de ser empreendedor e em seguida 
detectar uma oportunidade. Em pesquisa realizada por Gartner e Carter (apud ENGLE et al., 2010), 44\% dos empresários teve primeiro o desejo de iniciar um negócio, $34 \%$ tiveram primeiramente a ideia do negócio ou oportunidade e $21,5 \%$ sentiram que ambos vieram ao mesmo tempo. Em ambos os casos, segundo Engle et al. (2010), há uma intenção consciente por parte do indivíduo para se tornar um empreendedor.

Em pesquisa realizada por Mello et al. (2006) com sete empreendedores, a maior parte dos entrevistados associou o processo de reconhecimento de oportunidade aos seus interesses profissionais. Outro aspecto sinalizado pelos autores é o fato de estarem atentos aos nichos de mercados não atendidos e de necessitarem levantar informações sobre ele, além de buscarem conhecimentos relacionados aos esforços de marketing.

De acordo com Knudson et al. (2004), a intenção de iniciar e manter o comportamento empreendedor sofre a influência de vários fatores, dentre eles: as características individuais, o ambiente de negócios, metas pessoais, bem como a ideia de um negócio viável.

Em pesquisa realizada por Machado et al. (2003), com 90 empreendedoras, em três países, dentre eles o Brasil, a principal razão que as levaram a abrir um negócio foi à realização pessoal, seguido de percepção de oportunidade de mercado. De acordo com os estudos de Guedes (2009), os fatores motivadores para abrir um negócio foram: vontade de trabalhar por conta própria, desejo de independência, desejo de crescimento, vontade de superar desafios, oportunidade de trabalho, insatisfação com o emprego anterior.

A pesquisa realizada por Barros et al. (2005), na trajetória de vida de três empreendedores, constatou que no primeiro caso a oportunidade e a necessidade foram determinantes para a abertura do negócio. No segundo caso, o negócio iniciou com uma dona de casa que buscava complementar a renda da família e ocupar mais o seu tempo. No terceiro caso, a família influenciou na origem do negócio, o qual surgiu a partir da oportunidade percebida no mercado, conhecimento do negócio e experiência prévia.

Em pesquisa realizada por Jonathan e Silva (2007), com 49 empreendedoras cariocas, a trajetória delas foi marcada pela busca da autorrealização e no exercício do empreendedorismo, sentiam satisfação, se dedicavam com afinco e estavam profundamente comprometidas com seu negócio.
De acordo com Bernardi (2003), algumas circunstâncias podem levar o indivíduo a querer empreender, como: o indivíduo que demonstra traços de personalidade comuns do empreendedor nato; o herdeiro; o funcionário da empresa que sente ao longo da carreira um desequilíbrio e falta de reconhecimento; profissionais com características de empreendedor e que dispõem de know-how sobre algum tipo de serviço/ produto; vendedores entusiasmados e pelo conhecimento adquirido sobre o mercado e experiência profissional; profissional desempregado; funcionário que desenvolve um negócio ou se associa a outro ramo de atividade com um sócio capitalista; profissional aposentado. O autor também aponta como fator motivador a necessidade de realização, desejo de independência, fuga da rotina profissional, maior responsabilidade e riscos, maior possibilidade de ganho financeiro, status e controle sobre a qualidade de vida.

A família também é um dos fatores que influencia na abertura de novos negócios. Dos seis empreendedores pesquisados por Crespam et al. (2009), 50\% tiveram influência da família na decisão de abrir o negócio e os demais participantes contaram com o apoio da família e de amigos. Na pesquisa de Guedes (2009), a família também foi um ponto de apoio para que o empreendedor construísse sua carreira, pois $50 \%$ dos entrevistados afirmaram que pelo menos um dos seus pais era empreendedor. Na pesquisa realizada por Machado et al. (2003), 17,78\% dos casos teve o incentivo por parte dos familiares.

A família também pode ser empreendedora. Para Berent-Braun e Uhlaner (2010), a família empreendedora é formada de proprietários de negócios que partilham as responsabilidades para um resultado comum, que é o de preservar a riqueza alcançada.

\subsection{Fatores Motivadores que Antecedem a Escolha de Produtos, Serviços e Mercados}

Para Machado et al. (2003), a experiência anterior foi o fator antecedente mais relacionado com o ramo de atividade escolhido. Para Crespam et al. (2009), a experiência anterior ou a formação acadêmica, aliados ao aproveitamento de oportunidade no mercado, desencadearam a motivação para atuação na área do negócio. Outro fator foi à constituição de sociedade, pois dos seis entrevistados na pesquisa dos autores, 
$67 \%$ iniciaram o negócio em parceria com outros sócios. Para Bhide (2002) e Guedes (2009), os mercados, produtos ou serviços também são escolhidos na maioria dos casos em função da experiência e do conhecimento prévio no ramo aliados à oportunidade de mercado.

Em pesquisa realizada com os 100 fundadores das " 500 " empresas privadas de maior crescimento nos Estados Unidos (BHIDE, 2002), as razões que levam os empreendedores a escolher seu produto, serviço ou mercado podem ser diversos, dentre elas: pesquisa sistemática em busca de oportunidades; descobertas por acaso; transformação de um trabalho casual ou temporário; desejo de uma ideia como cliente individual; leu por acaso; desenvolveu a ideia de uma pessoa da família; copiou ou modificou uma ideia obtida através de um emprego anterior, entre outras.

Baseado na pesquisa teórico-empírica apresentada neste estudo pelos autores pesquisados observa-se que o comportamento empreendedor sofre a influência de alguns fatores: as características individuais, as experiências pessoais e os indicadores ambientais determinantes. O Quadro 1 apresenta um resumo desses fatores.

\begin{tabular}{|c|c|}
\hline $\begin{array}{l}\text { Características } \\
\text { individuais }\end{array}$ & $\begin{array}{l}\text { Assume riscos; criatividade; iniciativa; paixão } \\
\text { pelo que faz; inovação; aceita a possibilidade de } \\
\text { fracassar; vontade/motivação; busca mudança; } \\
\text { crença no que faz; motivação; percepção; } \\
\text { dedicação; comprometimento; liderança; busca } \\
\text { por desafios; busca por realização profissional, } \\
\text { desejo de independência, autonomia, coragem, } \\
\text { ousadia etc. }\end{array}$ \\
\hline $\begin{array}{l}\text { Experiências } \\
\text { pessoais }\end{array}$ & $\begin{array}{l}\text { Experiência prévia no ramo; modificação de uma } \\
\text { ideia obtida num emprego anterior; conhecimento } \\
\text { prévio/formação acadêmica; habilidades } \\
\text { gerenciais e operacionais desenvolvidas } \\
\text { em empregos anteriores; aprendizado com } \\
\text { empreendimentos anteriores; sociedade com } \\
\text { pessoas mais experientes; experiência adquirida } \\
\text { com os negócios da família, descoberta por } \\
\text { acaso etc. }\end{array}$ \\
\hline $\begin{array}{l}\text { Indicadores } \\
\text { ambientais }\end{array}$ & $\begin{array}{l}\text { Necessidade financeira; desemprego; insatisfação } \\
\text { com o trabalho anterior; falta de perspectiva } \\
\text { na carreira; fuga da rotina; reconhecimento de } \\
\text { oportunidade no mercado de acordo com os } \\
\text { interesses pessoais e profissionais; atenção aos } \\
\text { nichos de mercado não atendidos; influência } \\
\text { familiar; herança; aposentadoria etc. }\end{array}$ \\
\hline
\end{tabular}

Quadro 1: Características individuais, experiências pessoais $e$ indicadores ambientais

Fonte: Desenvolvido a partir da pesquisa teórico-empírica, segundo os autores pesquisados

\section{Empreendedorismo e Estratégia}

De acordo com Takahashi et al. (2006), o empresário é quase sempre o principal responsável pelo comportamento estratégico da empresa e pelo processamento de informações do ambiente. Ele tem clareza sobre seu direcionamento, mas não sistematiza formalmente o caminho que pretende seguir. Em sua pesquisa ficou constatado que poucas empreendedoras formalizaram sua missão e/ou a compartilharam. As empreendedoras pesquisadas eram menos predispostas ao risco e mais conservadoras e, os objetivos eram predominantemente econômicos. Eram mais orientadas para os negócios pela vocação, indicando um estilo de gestão mais voltado para a identidade do negócio $e$ menos estruturado em termos de modelos gerenciais. Para as autoras, nos casos analisados, o pensamento estratégico é artesanal, pois reage ao ambiente e a gestão é direcionada para a resolução de problemas que ocorrem no dia a dia.

Para Mello et al. (2006), em sua pesquisa com sete empreendedores dirigentes de empresas, o planejamento formal parece ser uma atividade alheia às práticas administrativas do dia a dia e a elaboração de um eventual plano de negócio tem validade somente no estágio de abertura da empresa, não sendo revisto posteriormente. Segundo Ansoff (1991), a introdução do planejamento se constitui num desafio para o empreendedor, pois este gera conflitos entre as operações já existentes e as atividades inovadoras.

Porter (2009, p. 43), considera que "[...] a essência da estratégia está nas atividades - a escolha entre executar as mesmas atividades de forma diferente ou de concentrar-se em atividades diferentes em comparação com os rivais".

Para Wall e Wall (1996), estratégia não envolve somente planejamento, mas também ação. Algumas vezes, a ação pode vir antes do planejamento. Por isso, esses autores preferem chamar de desenvolvimento estratégico ao invés de planejamento estratégico, que normalmente enfatiza o processo formal pelos quais as estratégias são elaboradas.

De acordo com Mintzberg e Quinn (2001), a noção de que estratégia é algo da administração do cotidiano de uma organização, é um dos maiores equívocos do gerenciamento estratégico convencional. 
A estratégia objetiva estabilidade a uma organização, pois a falta de estabilidade significa falta de estratégia.

Embora os conceitos estruturantes da estratégia englobem conteúdo e processo, neste trabalho foi dado especial destaque ao conteúdo estratégico. Ansoff (1991, p. 96) o define como "[...] quais produtos e tecnologias a empresa irá desenvolver, onde e para quem os produtos serão vendidos e como a empresa obterá vantagem sobre seus concorrentes". O conteúdo estratégico é de grande relevância para o empreendedor no que tange às suas definições quanto à escolha dos produtos, serviços e mercados em que pretende atuar.

Segundo Bulgacov et al. (2007), o conteúdo estratégico é um dos aspectos essenciais relacionados à estratégia, pois consiste em ver quais são os resultados obtidos pela organização quanto aos produtos oferecidos, mercados de atuação e objetivos alcançados. $\mathrm{O}$ conteúdo trata sobre o que a organização faz e de certa forma, define a razão de sua existência. Os estudos de conteúdo estratégico contemplam os seguintes temas: foco (mercados em que a empresa compete); modos de competição (estratégias corporativas, de negócios e funcionais); posição da empresa no ambiente; recursos estratégicos; desempenho e resultados estratégicos; e composto ou mix de marketing.

Nas decisões de negócios, os empreendedores podem promover mudanças no conteúdo estratégico optando por lançar novos produtos ou serviços. As razões para isso são várias, como: consumidores acostumados com o que tem podem procurar por novidades; o dinamismo da sociedade que altera os padrões, o poder aquisitivo, a expectativa de vida, os estilos de vida; avanços da tecnologia que melhoram produtos existentes e criam novos produtos; e ações dos concorrentes que lançam produtos originais ou copiam os já existentes (URDAN; URDAN, 2006). Segundo Knudson et al. (2004), as disposições pessoais, eventos da vida, mudanças na tecnologia, eventos que afetam o mercado, educação, permitem que as pessoas e as empresas sejam flexíveis o suficiente para mudar de um tipo de negócio para outro.

Para Hayashi Junior et al. (2006), na pesquisa realizada com três empresas industriais produtoras de massas alimentícias de pequeno porte, objetivou analisar as mudanças de conteúdo estratégico. Segundo os autores, cada mudança envolve a utilização da junção de certos recursos, os quais podem envolver desde o relacionamento com os fornecedores até a reputação da instituição no mercado visando à abertura de novas frentes de negócios.

As organizações, ao mesmo tempo em que mantêm o foco estratégico em atividades internas, podem ampliar tanto a oferta de produtos quanto o mercado de atuação, direcionando suas atividades para áreas que apresentem vantagem competitiva sobre os seus concorrentes. (BULGACOV et al., 2007)

\section{Metodologia}

Este estudo foi constituído de pesquisa descritiva e a estratégia de pesquisa empregada foi do tipo levantamento com aplicação de instrumentos para gerar dados estatísticos. Inicialmente foi feito uma pesquisa-piloto por meio de entrevista com seis empreendedores e na sequência foi construído um questionário, o qual se constituiu em investigação quantitativa. Os empreendedores pesquisados são dos Estados do Paraná, Santa Catarina e Rio Grande do Sul. O objetivo da pesquisa foi o de analisar e compreender os fatores motivadores do empreendedorismo que influenciam nas decisões de conteúdo estratégico na abertura de novos negócios.

Os seis empreendedores que participaram da pesquisa-piloto foram selecionados em função da caracterização enquanto pequena empresa e disponibilidade em responder o questionário, sendo quatro homens e duas mulheres; três são naturais do Paraná e três dos demais estados; cinco empreendedores têm formação acadêmica e pós-graduação em diferentes áreas; as empresas variam de pequenas a grande porte e os empreendimentos estão estabelecidos no mercado há 42 meses ou mais de acordo com o GEM (2009). Os empreendedores pertenciam aos seguintes ramos: Alimentação, Educação, Materiais de Construção, Fitness, Consultoria em Treinamento e Serviços de comunicação.

Posteriormente, a população que participou da pesquisa, foi por adesão com o objetivo de mensurar e quantificar os dados de um maior número de empreendedores. O questionário elaborado a partir da pesquisa-piloto foi enviado por e-mail aos empresários cadastrados nas Associações Comerciais estaduais, tendo obtido um total de 100 questionários respondi- 
dos. Foi analisado o perfil empreendedor desses empresários, os quais foram tratados neste estudo, como empreendedores. As empresas que participaram dessa etapa tinham entre um mês a mais de 10 anos, desde que estabelecidas formalmente no mercado.

O questionário foi elaborado com 24 questões visando à obtenção das seguintes informações: a) características pessoais; b) características do conteúdo estratégico; c) fatores motivadores na decisão de conteúdo estratégico; d) fatores motivadores na decisão de mudança de produtos, serviços e mercados; e) prováveis relações entre os fatores motivadores do empreendedorismo e as decisões de conteúdo estratégico.

A realização da pesquisa-piloto foi fundamental, pois as informações fornecidas pelos empreendedores, somadas às obtidas por meio da pesquisa teórico-empírica serviram de base para a elaboração do questionário utilizado.

A análise deste estudo foi feito através da comparação entre a pesquisa teórico-empírica e os resultados obtidos por meio do questionário e posteriormente foram contempladas as principais diferenças detectadas entre ambos.

Por utilizar o método quantitativo, os dados foram submetidos à análise estatística, com o auxilio do programa SPSS Statistics 17,0, estatística descritiva e comparações de médias.

\section{AnÁlise dos Dados}

A seguir, são apresentadas as características empreendedoras dos empresários pesquisados, as características de conteúdo estratégico, os fatores motivadores na escolha de produtos, serviços e mercados, na decisão de abrir um negócio, bem como os fatores motivadores na decisão de mudança quanto aos produtos, aos serviços e aos mercados. Por último, são apresentadas as prováveis relações entre fatores motivadores e as decisões de conteúdo estratégico.

\subsection{Características Empreendedoras}

Os empreendedores pesquisados, naturais de diversas cidades, como, Rio de Janeiro (RJ), Porto Alegre (RS), Curitiba (PR), São Paulo (SP), Medianeira (PR), São Miguel do Iguaçu (PR), Santa Maria (RS), Tapera
(RS), Recife (PE), entre outras, escolheram a região sul do país para estabelecer seus negócios e morar.

Quanto à participação de homens e mulheres na atividade empreendedora, a diferença foi relevante, sendo $65 \%$ do sexo masculino e $35 \%$ do sexo feminino, sendo que a média no Brasil, de acordo com o relatório GEM (2009), denota pouca diferença entre os sexos (mulheres $=53 \%$ e homens $=47 \%$ ).

A faixa etária que prevaleceu entre os empreendedores pesquisados foi entre 26 e 35 anos, com $32 \%$, corroborando com a média dos empreendedores brasileiros, que de acordo com o relatório GEM (2009), o maior índice é entre os 25 e os 34 anos, com 31,7\%. Entre os pesquisados, nesta faixa etária, contou com a participação de $43,7 \%$ do sexo feminino e $56,3 \%$ do sexo masculino.

Outro fator que influencia o comportamento empreendedor é a família. Nesta pesquisa, $42 \%$ dos empreendedores tiveram modelo de pais empreendedores. Nas pesquisas realizadas por Crespam et al. (2009) e por Guedes (2009), 50\% dos empreendedores também tiveram influência da família na decisão em abrir o negócio.

Quanto ao grau de instrução, 75\% tinham formação superior ou pós-graduação. Na pesquisa realizada por Machado et al. (2003), com 90 empreendedoras, $63,28 \%$ eram graduadas ou pós-graduadas. Também no estudo realizado por Crespam et al. (2009), 83,33\% dos entrevistados eram graduados ou buscavam uma pós-graduação. É provável que nesta pesquisa, a formação acadêmica tenha influenciado nas decisões de conteúdo estratégico, pois o conhecimento teórico/ formação obteve a maior pontuação quanto ao fator motivador para abrir o negócio.

As características pessoais que mais se destacaram foram: vontade/motivação e determinação com $12 \%$, seguidos por coragem e ousadia com $9,2 \%$, conforme mostra a Tabela 1 . As características vontade e motivação foram citadas por Angelo (2003), Costigan et al. (2006) e Knudson et al. (2004), determinação foi citada por um dos empreendedores na pesquisa-piloto, não sendo citada por outros autores pesquisados neste estudo; coragem e ousadia foram citadas por Crespam et al. (2009). A característica que obteve o menor escore foi assumir riscos, com $3,2 \%$, sendo esta comum aos empreendedores, se acordo com os diversos autores no inicio deste estudo. Também, na pesquisa de Takahashi 
et al. (2006), as empreendedoras pesquisadas eram menos propensas ao risco, pois eram mais conservadoras e mais orientadas para o negócio pela vocação.

Tabela 1: Características pessoais

\begin{tabular}{|c|c|c|}
\hline & \multicolumn{2}{|c|}{ RESPONSES } \\
\hline & $\mathbf{N}$ & Percent (\%) \\
\hline Determinação & 30 & 12,00 \\
\hline Vontade/motivação & 30 & 12,00 \\
\hline Coragem/ousadia & 23 & 9,20 \\
\hline Busca por inovação & 22 & 8,80 \\
\hline Iniciativa & 22 & 8,80 \\
\hline Comprometimento & 22 & 8,80 \\
\hline Busca por desafios & 19 & 7,60 \\
\hline Liderança & 18 & 7,20 \\
\hline Persistência & 17 & 6,80 \\
\hline Dedicação & 17 & 6,80 \\
\hline Criatividade & 14 & 5,60 \\
\hline Dinamismo & 9 & 3,60 \\
\hline Assume riscos & 8 & 3,20 \\
\hline Total & 251 & 100,00 \\
\hline
\end{tabular}

Nota: Respostas múltiplas - $251 \mathrm{p} / 88$

Fonte: Elaborada pelos autores deste artigo com base nos dados da pesquisa

\subsection{Características de Conteúdo Estratégico}

Os empreendimentos pesquisados apresentaram as seguintes características: o ramo de atividade para $62,8 \%$ foi na área de serviços, $27,4 \%$ no comércio e $9,7 \%$ na indústria, sendo que alguns empreendedores atuavam em mais de um ramo de atividade. O ramo de serviços contou com a atuação de $62,9 \%$ das empreendedoras e com 75,4\% dos empreendedores, sendo a faixa etária predominante entre os 36 e os 45 anos, com $33,8 \%$, seguido da faixa etária dos 26 aos 35 anos, com $31 \%$. Segundo o relatório GEM (2009), o empreendedorismo no Brasil é marcado por negócios com foco em serviços, orientados para o consumidor final.

$\mathrm{O}$ mercado de atuação mais relevante foi à própria localidade de atuação, com $32 \%$, seguido do próprio Estado e outros estados, com $25 \%$ dos empre- endimentos. Embora tenha predominado o ramo de serviços na análise dos ramos de atividades por região de atuação, nos bairros, o comércio foi mais relevante, obtendo $50 \%$.

Os produtos e serviços comercializados pelos empreendedores pesquisados foram bastante diversificados, dentre eles: consultoria, com $19,3 \%$, assistência à saúde, com $8,8 \%$ e equipamentos e produtos/bens móveis, com 7,9\%. Observa-se que consultoria, no ramo de serviços, obteve significativa vantagem sobre os demais.

Nesta pesquisa, $55 \%$ estavam no primeiro empreendimento e $62 \%$ estavam no mercado há mais de cinco anos. De acordo com Dornelas (2001) muitos empreendedores só conseguem ser bem-sucedidos no segundo ou terceiro empreendimento e segundo as estatísticas do SEBRAE (acesso em 2010), o índice de mortalidade nos primeiros cinco anos é de $70 \%$ ou mais. A maioria dos empreendedores que participou desta pesquisa está no primeiro empreendimento e já superou a fase crítica de mortalidade.

Quanto às estratégias utilizadas para competir no mercado, 19,9\% dos empreendedores procuraram criar um diferencial competitivo, principal estratégia para os três ramos de atividade, sendo uma das opções para $50 \%$ das empreendedoras e $58 \%$ dos empreendedores. Importante ressaltar que $38,8 \%$ dos empreendedores tinham entre 26 e 35 anos. Outras estratégias que obtiveram destaque foram: investimento no atendimento, com $15 \%$ e, marketing boca a boca, $12,6 \%$, conforme mostra a Tabela 2. Um fator interessante é que aqueles que estavam em seu primeiro empreendimento foram os que mais investiram em estratégias, de modo geral.

Quanto às bases utilizadas pelos empreendedores para a tomada de decisões, $42,9 \%$ atuaram de acordo com a demanda de mercado/clientes e 39,7\% com base no planejamento estratégico anual. Segundo Bhide (2001) é importante a experiência e o know-how no planejamento estratégico, pois este muito poderá auxiliar na redução de prováveis erros num novo negócio.

Quanto à tomada de decisões na empresa, $52 \%$ dos empreendedores decidiam em conjunto com os sócios ou gerentes, $26 \%$ decidiam sozinhos por não terem sócios e 19\% decidiam sozinhos, apesar de terem sócios. Observa-se que quem decide junto com os sócios ou gerentes utiliza tanto o planejamento como a atuação de acordo com a demanda de mercado. 
Tabela 2: Estratégias utilizadas para competir no mercado

\begin{tabular}{|l|c|c|} 
& \multicolumn{2}{c}{ RESPONSES } \\
\cline { 2 - 3 } & & PERCENT \\
\hline Procura criar um diferencial competitivo & 49 & $\mathbf{( \% )}$ \\
\hline Investe no atendimento & 37 & 15,90 \\
\hline Marketing boca a boca & 31 & 12,60 \\
\hline $\begin{array}{l}\text { Trabalha em cima de resultados } \\
\text { (relacionados aos objetivos) }\end{array}$ & 30 & 12,20 \\
\hline Treinamento de funcionários & 24 & 9,80 \\
\hline Procura oferecer maior variedade & & \\
\hline de produtos/ serviços & 24 & 9,80 \\
\hline Mídia & 18 & 7,30 \\
\hline Promoções & 11 & 4,50 \\
\hline Panfletagem & 8 & 3,30 \\
\hline Política de preços baixos & 8 & 3,30 \\
\hline Telemarketing & 4 & 1,60 \\
\hline Qualidade nos serviços & 246 & 0,80 \\
\hline Total & 100 \\
\hline
\end{tabular}

Nota: Respostas múltiplas - 246 p/ 89

Fonte: Elaborada pelos autores deste artigo com base nos dados da pesquisa

Tabela 3: Modo como obtém informações sobre o mercado

\begin{tabular}{|lcc|} 
& \multicolumn{2}{c|}{ RESPONSES } \\
\cline { 2 - 3 } & N & PERCENT (\%) \\
\hline Através de clientes/ fornecedores & 72 & 30,60 \\
\hline $\begin{array}{l}\text { Faz pesquisa de mercado/ } \\
\text { internet/ revistas especializadas }\end{array}$ & 62 & 26,40 \\
\hline $\begin{array}{l}\text { Participa de associações/ } \\
\text { reuniões do ramo }\end{array}$ & 36 & 15,30 \\
\hline Analisa as ações dos concorrentes & 33 & 14,00 \\
\hline Faz levantamento de preços & 19 & 8,10 \\
\hline Cliente oculto & 5 & 2,10 \\
\hline Franquia & 5 & 2,10 \\
\hline Telemarketing & 3 & 1,30 \\
\hline Total & 235 & 100,00 \\
\hline
\end{tabular}

Nota: Respostas múltiplas - 235 p/ 94

Fonte: Elaborada pelos autores deste artigo com base nos dados da pesquisa
Já aqueles que trabalhavam sozinhos, por não terem sócios, a atuação foi maior pela demanda de mercado e, os que trabalhavam sozinhos embora tendo sócios, a atuação foi maior pelo planejamento estratégico.

Quanto ao modo como os empreendedores adquiriam informações sobre o mercado, $30,6 \%$ obtinham por meio de clientes e fornecedores, $26,4 \%$ por meio de pesquisa de mercado (internet, revistas especializadas, jornais, entre outros), e 15,3\% participavam de reuniões do ramo ou de associações, conforme mostra a Tabela 3.

Quanto às expectativas iniciais de seus negócios, $34 \%$ dos empreendedores tinham uma expectativa mediana e para $42 \%$ as perspectivas atuais eram muito boas. Observa-se que as perspectivas atuais foram melhores do que o esperado inicialmente.

\subsection{Fatores Motivadores que Atuaram como Precursores na Escolha de Produtos, Serviços e Mercados}

Os fatores que mais contribuíram na escolha de produtos, serviços e mercados foram: conhecimento teórico/formação com $35,3 \%$; a experiência prévia no ramo com $25,2 \%$; seguido de sociedade com pessoas mais experientes, com $12,2 \%$, conforme mostra a Tabela 4. Para Machado et al. (2003), Crespam et al. (2009), Guedes (2009) e Bernardi (2003), a experiência prévia ou o conhecimento prévio/formação acadêmica também antecedem à escolha do ramo de negócio. $\mathrm{Na}$ pesquisa de Crespam et al. (2009) 66\% dos entrevistados também iniciaram parceria com outros sócios. Para Bernardi (2003), várias são as circunstâncias que podem levar um indivíduo a empreender, dentre elas a sociedade com um sócio capitalista.

Nesta pesquisa, $79 \%$ dos empreendedores tinham de médio a muito conhecimento sobre o seu negócio. De acordo com as pesquisas do SEBRAE (acesso em 2010) quanto maior o conhecimento e as experiências vividas no negócio que se pretende atuar, maiores são as chances de o empreendimento ser bem-sucedido. Talvez isso possa explicar as perspectivas positivas para a maioria dos pesquisados neste estudo. 
Tabela 4: Fatores motivadores na escolha de produtos, serviços e mercados

\begin{tabular}{|l|c|c|} 
& \multicolumn{2}{c}{ RESPONSES } \\
\cline { 2 - 3 } & N & PERCENT (\%) \\
\hline Conhecimento teórico/formação & 49 & 35,3 \\
\hline Experiência prévia no ramo & 35 & 25,2 \\
\hline $\begin{array}{l}\text { Sociedade com pessoas mais } \\
\text { experientes no ramo }\end{array}$ & 17 & 12,2 \\
\hline Fez uma pesquisa no mercado & 10 & 7,2 \\
\hline $\begin{array}{l}\text { Descoberta por acaso } \\
\text { Seguiu os negócios da família }\end{array}$ & 9 & 6,5 \\
\hline $\begin{array}{l}\text { Modificou uma ideia obtida } \\
\text { num emprego anterior }\end{array}$ & 6 & 5,8 \\
\hline Oportunidade & 4 & 4,3 \\
\hline Depressão & 1 & 2,9 \\
\hline Total & 139 & 100,0 \\
\hline
\end{tabular}

Nota: Respostas múltiplas - 139 p/ 100

Fonte: Elaborada pelos autores deste artigo com base nos dados da pesquisa

\subsection{Fatores Motivadores que Atuaram Como Precursores na Decisão de Abrir o Negócio}

Os fatores que mais contribuíram na decisão de abrir o negócio foram: oportunidade no mercado com $18,8 \%$; seguido de realização profissional com $16,5 \%$ e desejo de independência com 15,8\%, conforme mostra a Tabela 5. Para Dornelas (2001), o empreendedor ao perceber uma oportunidade no mercado cria um negócio e para Drucker (2003), o empreendedor aproveita a oportunidade ao buscar a mudança. Machado et al. (2003), Bernardi (2003), Jonathan e Silva (2007) citaram a necessidade de realização pessoal como fator propulsor para abrir o negócio; desejo de independência foi citada por Crespam et al. (2009), Guedes (2009) e Bernardi (2003).

De acordo com o relatório GEM (2009), os fatores motivadores para a abertura de novos negócios apresentam duas forças propulsoras: a oportunidade e a necessidade. Dentre os motivos apontados pelos empreendedores pesquisados, $18,8 \%$ abriram o negócio por terem visto uma oportunidade no mercado e $8,5 \%$ abriram por necessidade financeira, dentre outros.
Tabela 5: Fatores motivadores quanto a querer abrir o negócio

\begin{tabular}{|l|c|c|}
\hline & \multicolumn{2}{c}{ RESPONSES } \\
\cline { 2 - 3 } & PERCENT & (\%) \\
\hline Viu uma oportunidade no mercado & 49 & 18,80 \\
\hline Realização profissional & 43 & 16,50 \\
\hline Desejo de independência & 41 & 15,80 \\
\hline Desejo de crescimento & 33 & 12,70 \\
\hline Busca por desafios & 23 & 8,80 \\
\hline Necessidade financeira & 22 & 8,50 \\
\hline Desejo de trabalhar por conta própria & 19 & 7,30 \\
\hline Qualidade de vida & 11 & 4,20 \\
\hline Encontrou um sócio motivado & 7 & 2,70 \\
\hline Fuga da rotina & 3 & 1,20 \\
\hline Insatisfação com o trabalho & 1 & 0,40 \\
\hline anterior/ falta de perspectiva & 260 & 100,00 \\
\hline Desemprego & 3 & 1,20 \\
\hline Está aposentado & 3 & 1,20 \\
\hline Influência familiar & 1 & 0,40 \\
\hline Vontade de fazer diferente & & 0,40 \\
\hline Total & 3 & \\
\hline & 3 & \\
\hline
\end{tabular}

Nota: Respostas múltiplas - 260 p/ 92

Fonte: Elaborada pelos autores deste artigo com base nos dados da pesquisa

\subsection{Fatores Motivadores que Atuaram como Precursores na Decisão de Mudança de Produtos, Serviços e Mercados de seus Negócios}

Os fatores que mais contribuíram na decisão de mudança, desde a escolha inicial de seus negócios foram: mudança no modo de atuar no mercado, com $36,8 \%$; mudança em alguns produtos ou serviços, com $29,1 \%$ e não efetuaram mudança em seus negócios, com $15,4 \%$, conforme mostra a Tabela 6 . Um fator a ser considerado é que a maioria dos pesquisados vieram de outras cidades para se estabelecer na região de atuação, provavelmente exigindo algum nível de adaptação à cultura local. No estudo realizado por Hayashi Junior et al. (2006), em três empresas pesquisadas também se buscou efetuar mudanças, procurando desenvolver 
novos produtos para o mercado atual e novos mercados para os produtos já existentes.

Tabela 6: Mudanças ocorridas desde a escolha inicial do negócio

\begin{tabular}{|c|c|c|}
\hline & \multicolumn{2}{|c|}{ RESPONSES } \\
\hline & $\mathbf{N}$ & Percent (\%) \\
\hline $\begin{array}{l}\text { Mudança no modo de } \\
\text { atuar no mercado }\end{array}$ & 43 & 36,8 \\
\hline $\begin{array}{l}\text { Mudança em alguns } \\
\text { produtos/ serviços }\end{array}$ & 34 & 29,1 \\
\hline Não houve mudanças & 18 & 15,4 \\
\hline $\begin{array}{l}\text { Mudança em vários } \\
\text { produtos/ serviços }\end{array}$ & 13 & 11,1 \\
\hline $\begin{array}{l}\text { Mudança radical no } \\
\text { ramo de negócio }\end{array}$ & 9 & 7,7 \\
\hline Total & 117 & 100,0 \\
\hline
\end{tabular}

Nota: Respostas múltiplas - 117 p/100

Fonte: Elaborada pelos autores deste artigo com base nos dados da pesquisa

Os fatores motivadores que mais se destacaram para mudanças nos negócios foram: detectou uma oportunidade mais atrativa no mercado, com $29,5 \%$; avanços da tecnologia com $21,4 \%$; e o dinamismo da sociedade com $16,1 \%$, conforme mostra a Tabela 7. De acordo com Urdan e Urdan (2006), os empreendedores podem efetuar mudanças no conteúdo estratégico por várias razões, dentre elas o dinamismo da sociedade e os avanços da tecnologia, dentre outras. Para Knudson et al. (2004), as empresas não precisam ficar presas a um único tipo de negócio, pois as mudanças na tecnologia, eventos que afetam o mercado, permitem que elas sejam flexíveis o suficiente para mudar de um tipo de negócio para outro.

\subsection{Prováveis Relações entre os Fatores Motivadores e as Decisões de Conteúdo Estratégico}

Dentre os empreendedores pesquisados que optaram pela alternativa conhecimento teórico/formação (35,3\%), na escolha de produtos e serviços, o fator motivador para a abertura do negócio que mais influenciou foi o desejo de realização profissional, sendo a região de atuação atual a de maior relevância, com 19\%. É provável que esses empreendedores tivessem
Tabela 7: Fatores motivadores para mudança

\begin{tabular}{|l|c|c|}
\hline \multicolumn{2}{|c|}{ RESPONSES } \\
\hline & N & PERCENT (\%) \\
\hline $\begin{array}{l}\text { Detectou outra oportunidade } \\
\text { mais atrativa }\end{array}$ & 33 & 29,5 \\
\hline Avanços da tecnologia & 24 & 21,4 \\
\hline Dinamismo da sociedade & 18 & 16,1 \\
\hline O mercado não era promissor & 13 & 11,6 \\
\hline Concorrência & 10 & 8,9 \\
\hline $\begin{array}{l}\text { Falta de conhecimento/ } \\
\text { experiência }\end{array}$ & 4 & 3,6 \\
\hline Mudou de cidade/ estado/ país & 3 & 2,7 \\
\hline Os sócios saíram do negócio & 3 & 2,7 \\
\hline Falência/dívidas da empresa & 2 & 1,8 \\
\hline Redefinição de foco & 1 & 0,9 \\
\hline Feedback do cliente & 1 & 0,9 \\
\hline Total & 112 & 100,0 \\
\hline
\end{tabular}

Nota: Respostas múltiplas - 112 p/ 73

Fonte: Elaborada pelos autores deste artigo com base nos dados da pesquisa

algum nível de insatisfação profissional e em função do conhecimento teórico/formação acadêmica viram a possibilidade de realização profissional com a abertura de um negócio.

O segundo fator na escolha de produtos, serviços e mercados foi à experiência prévia no ramo $(25,2 \%)$. Destes, o fator motivador que mais influenciou na abertura do negócio foi a oportunidade vista no mercado, sendo a região de maior atuação no município de atuação, com $10 \%$. É provável que a experiência em empregos anteriores tenha favorecido o reconhecimento de uma oportunidade no mercado. Segundo Miao e Liu (2010) e Mello et al. (2006), o conhecimento prévio antecede o reconhecimento de oportunidades e impacta diretamente nas decisões estratégicas.

O terceiro fator na escolha de produtos, serviços e mercados foi estabelecer sociedade com pessoas mais experientes no ramo (12,2\%). Destes, o fator motivador que mais influenciou para a abertura do negócio foi a oportunidade no mercado, sendo a região de maior atuação, com 7\%. No entanto, nenhum desses empreendedores abriu seu negócio no bairro. É provável que os empreendedores no contato com outras pessoas 
mais experientes tenham visto na experiência do sócio uma oportunidade para se estabelecer no mercado.

Dentre aqueles que mudaram o modo de atuar no mercado $(36,8 \%)$, as decisões eram tomadas com base na demanda de mercado/clientes. Os principais fatores motivadores foram os avanços da tecnologia, principalmente, seguido do fato de ter detectado outra oportunidade mais atrativa no mercado e o dinamismo da sociedade, ambos com o mesmo percentual. Obtinham informações sobre o mercado, por meio de clientes e fornecedores, seguido de pesquisa de mercado. Como estratégia principal, procuraram criar um diferencial competitivo.

Dentre aqueles que mudaram alguns produtos ou serviços $(29,1 \%)$, as decisões foram tomadas principalmente com base no planejamento estratégico. Os principais fatores motivadores foram os avanços da tecnologia, seguido do fato de ter detectado outra oportunidade mais atrativa no mercado, seguido do dinamismo da sociedade. As informações sobre o mercado eram obtidas por meio de clientes e fornecedores, seguida de pesquisa de mercado. Como estratégia principal, eles procuraram criar um diferencial competitivo.

Dentre aqueles que não efetuaram mudanças $(15,4 \%)$, as decisões foram tomadas de acordo com a demanda de mercado, principalmente. Obtinham informações sobre o mercado de atuação por meio de pesquisa de mercado, seguido de clientes e fornecedores. Como estratégia principal, procuraram investir no atendimento ao cliente. Importante ressaltar que eles foram os que mais investiram em mídia, promoções, treinamento, panfletagem e em maior variedade de produtos/serviços e, no entanto, não efetuaram mudanças em seus negócios.

\section{Considerações Finais}

Esse estudo, de caráter descritivo, pretendeu analisar e compreender os fatores motivadores do empreendedorismo que influenciaram nas decisões de conteúdo estratégico nas empresas do sul do país, propondo delinear as principais características empreendedoras dos empresários pesquisados e, de seus empreendimentos; os fatores motivadores na escolha de produtos, serviços e mercados; os fatores motivadores para a abertura do negócio; mudanças nos produtos, serviços e mercados, bem como as relações entre os fatores motivadores e conteúdo estratégico.

Foi feita a análise entre os fatores motivadores do empreendedorismo e conteúdo estratégico, mas não teve a pretensão de abarcar todos os aspectos relacionados ao tema e nem dar por concluído os achados. Trata-se de um tema relevante para todos os que têm a pretensão de abrir o seu negócio, bem como para aqueles que já têm um negócio estabelecido. No entanto, a literatura envolvendo os dois aspectos é escassa, requerendo a premência de novos estudos.

As características empreendedoras e dos seus empreendimentos foram analisadas, fazendo-se uma correlação entre elas. Concluiu-se que algumas das características empreendedoras encontradas nos empresários pesquisados, também, foram apontadas por outros autores no início deste estudo, porém assumir risco, característica comum nos empreendedores, obteve o menor escore. Também foram considerados os fatores motivadores na decisão de conteúdo estratégico, bem como o histórico de pais empreendedores.

Embora os estudos no Brasil apontem para o empreendedorismo feminino com maior atuação, neste estudo prevaleceu o empreendedorismo masculino.

Nos empreendimentos analisados, estabelecidos na região sul do país, os produtos e serviços comercializados foram os mais diversos, bem como os ramos de atuação. Foram consideradas as empresas que estão no mercado entre um mês até mais de dez anos, desde que estabelecidas formalmente.

Tanto os fatores motivadores para abrir um negócio quanto à escolha de produtos/serviços e mercados, apresentaram semelhanças quando comparados com a literatura específica. No entanto, quanto às estratégias utilizadas pelos empreendedores, não foram encontrados outros estudos que tratassem desses aspectos para prováveis comparações.

É importante destacar que os resultados obtidos neste estudo restringem-se apenas aos casos que foram analisados, não podendo ser generalizado para a região em questão e nem para o país.

Neste estudo foram analisados apenas os casos que obtiveram êxito, sendo necessário também pesquisar os empreendimentos que não obtiveram bons resultados em pesquisas futuras. 


\section{REFERÊNCIAS}

ANGELO, E. B. Empreendedor corporativo: a nova postura de quem faz a diferença. Rio de Janeiro: Campus, 2003.

ANSOFF, I. A nova estratégia empresarial. São Paulo: Atlas, 1991.

BARROS. F. S. O.; FIÚSA, J. L. A.; IPIRANGA, A. S. R. O Empreendedorismo como Estratégia Emergente de Gestão: histórias de sucesso. O\&S, Salvador, BA.v. 12, n. 33, abr.-jun. 2005.

BERENT-BRAUN, M. M.; UHLANER, L. M. Family Governance Practices and Teambuilding: paradox of the enterprising family. Small Business Economics, Netherlands, March, 10, 2010.

BERNARDI, L. A. Manual de Empreendedorismo e Gestão. São Paulo: Atlas, 2003.

BHIDE, A. Como os empreendedores moldam estruturas que funcionam. In: MINTZBERG, H.; QUINN, J.B. O

Processo da Estratégia. 3. ed. Porto Alegre: Bookman, 2001.

BHIDE, A. Como os empreendedores constroem estratégias que dão certo. In: Empreendedorismo e Estratégia. São Paulo: Campus, 2002.

BULGACOV, S. et al. Administração Estratégica: teoria e prática. São Paulo: Atlas, 2007.

CAROLIS, D. M.; SAPARITO, P. Social Capital, Cognition, and Entrepreneurial Opportunities: A Theoretical Framework. Entrepreneurship Theory and Practice, USA, v. 30, n. 1, p. 41-56; 2006.

COSTIGAN, R. D.; INSINGA, R.C.; BERMAN, J.J.; ILTER, S.; KRANAS, G.; KURESHOV, V. The Effect of Employer Trust of the Supervisor on Enterprising

Behavior: a cross-cultural comparison. Journal of Business and Psychology, USA, v. 21, n. 2, 2006.

CRESPAM, C. C.; FONSECA, J. L.; GROHMANN, M.

Z. Evidências Empiricas do Perfil Empreendedor: um Estudo do Modelo de Motivações Empreendedoras. IV

Encontro de Estudos em Estratégia, Recife (PE), 21 a 23 de junho, 2009.

\section{DORNELAS, J. C. A. Empreendedorismo:}

transformando ideias em negócios. Rio de Janeiro: Campus, 2001.

DRUCKER, P. F. Inovação e Espírito Empreendedor. São Paulo: Pioneira, 2003.

ENGLE, R. L. DIMITRIADI, N.; GAVIDIA, J.V.; SCHLAEGEL, C.; DELANOE, S.; ALVARADO, I.; He, X.; BUAME, S.; WOLFF, B. Entrepreneurial intent: A TwelveCountry Evaluation of Ajzen's Model of Planned Behavior. International Journal of Entrepreneurial Behaviour \& Research, United Kingdom, v. 16, n. 1, 2010.

FILLION, L. J. Empreendedorismo: empreendedores e proprietários-gerentes de pequenos negócios. Revista de Administração, São Paulo, v. 34, n. 2, p. 5-28, abr.-jun. 1999.

GARTNER, W. B. Who Is an Entrepreneur? Is the Wrong Question. American Journal of Small Business, USA, v. 13, n. 4 , p. 47-68, 1988.

GELDEREN, M. V. Enterprising Behaviour of Ordinary People. European Journal of Work \& Organizational Psychology, Netherlands, v. 9, n. 1, p. 81-88, mar. 2000.

GEM 2009 - Global Entrepreneurship Monitor 2009. Empreendedorismo no Brasil 2009. Curitiba: IBPQ, 2010. 165 p.

GUEDES, S. A. A carreira do Empreendedor. (Dissertação de Mestrado em Administração). Programa de pós-graduação em Administração da USP, São Paulo, p. $88,89,95,98,110$ e 111, 2009. 160 p.

HAYASHI JR., P.; BARANIUK, J. A.; BULGACOV, $\mathrm{S}$. Mudança de Conteúdo Estratégico em Pequenas Empresas de Massas Alimentícias. Revista de Administração Contemporânea - RAC, Rio de Janeiro (RJ), v. 10, n. 3, jul.-set. 2006.

JONATHAN, E. G.; SILVA, T. M. R. Empreendedorismo Feminino: Tecendo a Trama de Demandas Conflitantes.

Psicologia \& Sociedade, Porto Alegre, RS, v. 19, n. 1, p. 77-84, jan.-abr. 2007.

KNUDSON, W. et al. Entrepreneurship and Innovation in the Agri-Food System. American Journal of Agricultural Economics, USA, v. 86, n. 5, p. 1.330 $-1.336,2004$. 
MACHADO, H. V. et al. O processo de Criação de

Empresas por Mulheres. RAE - Eletrônica, [on-line], v. 2, n. 2, jul.-dez. 2003.

MATS, W.; WINCENT, J. CEO Succession, Honing, and Enterprising: a promising way to achieve a small business performance? Journal of Developmental Entrepreneurship, Sweden, v. 13, n. 2, p. 117-132, 2008.

MELLO, S. C. B. et al. Competências Empreendedoras de Dirigentes de Empresas Brasileiras de Médio e Grande Porte que Atuam em Serviços da Nova Economia.

Revista de Administração Contemporânea - RAC, Rio de Janeiro (RJ), v. 10, n. 4, p. 47-69, out.-dez. 2006.

MIAO, Q.; LIU, L.A Psychological Model of

Entrepreneurial Decision Making. Social Behavior and

Personality, v. 38, n. 3, p. 357-363, 2010,

MINTZBERG, H.; QUINN, J. B. O Processo da Estratégia.

3. ed. Porto Alegre: Bookman, 2001.

PORTER, M. E. Competição: on competition. Rio de Janeiro: Elsevier, 2009.

\section{SCHUMPETER, J. Teoria do desenvolvimento}

econômico. São Paulo: Abril Cultural, 1982.

SERVIÇO Brasileiro de Apoio às Micro e Pequenas Empresas (SEBRAE). [2010]. Disponível em: <http:// www.sebraepr.com.br/>. Acesso em: 2 maio 2010.

TAKAHASHI, A. R. W.; GRAEFF, J. F.; TEIXEIRA, R. M. Planejamento estratégico e Gestão Feminina em Pequenas Empresas: o Caso das Escolas Particulares em Curitiba Paraná. Anais do IV EGEPE - Encontro de Estudos sobre Empreendedorismo e Gestão de Pequenas Empresas, Curitiba, 2005, p. 872-884. Anais... Curitiba, 2005.

URDAN, F. T.; URDAN, A. T. Gestão do composto de marketing. São Paulo: Atlas, 2006.

VALLIERE, D. Reconceptualizing Enterpreneurial Framework Conditions. International

Entrepreneurship and Management Journal,

Canada, v. 6, n. 1, 2010.

WALL, S. J.; WALL, S. R. Os novos estrategistas: criando líderes em todos os níveis da organização. São Paulo: Futura, 1996. 